\title{
A Novel Minimally Invasive Surgical Technique for Fragility Fractures of the Pelvis with Iliac Screws via Two Small Incisions
}

\author{
Mitsuru Asukai ( $\square$ mitsuruasukai@gmail.com ) \\ Hokkaido Spinal Cord Injury Center \\ Kota Suda \\ Hokkaido Spinal Cord Injury Center \\ Matsumoto Satoko \\ Hokkaido Spinal Cord Injury Center \\ Miki Komatsu \\ Hokkaido Spinal Cord Injury Center \\ Masahiko Takahata \\ Hokkaido University Hospital \\ Norimasa Iwasaki \\ Hokkaido University Hospital \\ Yukihiro Matsuyama \\ Hamamatsu University School of Medicine \\ Akio Minami \\ Hokkaido Spinal Cord Injury Center
}

Research Article

Keywords: fragility fractures of the pelvis (FFP), ageing of society, immobilization, posterior superior iliac spine

Posted Date: January 14th, 2021

DOI: https://doi.org/10.21203/rs.3.rs-127762/v1

License: (c) (1) This work is licensed under a Creative Commons Attribution 4.0 International License. Read Full License 


\section{Abstract}

The number of fragility fractures of the pelvis (FFP) is increasing quickly due to the ageing of society, and the treatment remain controversial. Long-term immobilization during conservative treatment can lead to secondary systemic complications, conventional open reduction and internal fixation is highly invasive. We have developed a novel minimally invasive surgical technique for FFP. We made a 3$\mathrm{cm}$ incision along medial borders of the posterior superior iliac spine, inserted one iliac screw on each side, and created a tunnel below the fascia connecting the two incisions. The interconnecting rod was slid across the tunnel on the dorsal surface of the sacrum and then fixed with iliac screws. We evaluated the outcomes of this new stabilization technique in 9 patients, the average age and follow-up period were 80.8 years and 10.0 months. According to the Rommens classification, there was 1 patient with IIllc fracture, 1 with IVa, 6 with IVb and 1 with IVc. The average surgical time was 60.7 minutes with an intraoperative blood loss of $2.0 \mathrm{ml}$, and bony union of the posterior part of the pelvic ring was achieved in all patients. This method is a useful and safe minimally invasive option for high-risk elderly patients.

\section{Introduction}

The number of fragility fractures of the pelvis (FFP) is increasing along with the rapid ageing of the population and the increase in osteoporotic patients $^{1-3}$. FFP occur in elderly, severe osteoporotic and frail patients who have several comorbidities, such as anaemia, malnutrition, cardiopulmonary insufficiency and renal dysfunction, and these fractures are treated conservatively in many cases. However, conservative treatment requiring long-term immobilization has a major impact on not only activities of daily living but also the incidence of systemic complications such as aspiration pneumonia, urinary tract infection, decubitus and disuse syndrome ${ }^{4}$. Moreover, nonunion development and/or fracture progression of the pelvic ring are often detected in patients with FFP during conservative treatment, which leads to physical dysfunction ${ }^{5}$. Because conventional open reduction and internal fixation (ORIF) such as spino-pelvic fixation is highly invasive, there are limitations to applying ORIF in elderly patients with poor general conditions. Our novel minimally invasive surgical (MIS) technique has an advantage for FFP in elderly patients with poor conditions.

\section{Surgical Technique}

In a prone position under general anaesthesia, we made two $3-\mathrm{cm}$ incisions along the right and left medial borders of the posterior superior iliac spine (PSIS). Minimal bone resection of the posterior top of the PSIS was performed to prevent protrusion of the heads of the screws and postoperative irritation (Fig. 1a). We inserted one iliac screw (6.5-8.5 mm in diameter) on each side using fluoroscopy (Fig. 1b) and created a tunnel below the fascia connecting the two incisions for the passage of the rod. After rod contouring to avoid the median sacral crest, the interconnecting rod was slid across the tunnel on the dorsal surface of the sacrum and then fixed with iliac screws (Fig. 1c, 1d). Patients were allowed non-weight bearing for a period of 2-4 weeks after surgery, and then full weight bearing was allowed depending on their tolerance.

\section{Results}

Table 1 shows the demographic details of the 9 patients. The average time of the surgical procedure was 60.7 minutes (range, 41-90 minutes), with an intraoperative blood loss of $2.0 \mathrm{ml}$ (range, 1-10 ml). Postoperative complications developed in 4 patients: 2 with wound dehiscence requiring re-suture, 1 with deep vein thrombosis and 1 with lower gastrointestinal bleeding. There were no systemic complications, such as aspiration pneumonia or urinary tract infection. Bony union of sacral fractures, which occur in the posterior part of the pelvic ring, was achieved in all patients $(100 \%)$. Five patients recovered their walking abilities to preinjury levels. The mean BMD T-score was - 3.4, and we prescribed daily teriparatide in 3 patients, romosozumab in 2 patients and denosumab in 2 patients for osteoporosis treatment. 
Table 1

Demographic details of the 9 patients

\begin{tabular}{|c|c|c|c|c|c|c|c|c|c|c|}
\hline \multirow{2}{*}{$\begin{array}{l}\text { Age/ } \\
\text { Gender }\end{array}$} & \multirow{2}{*}{$\begin{array}{l}\text { Past } \\
\text { medical } \\
\text { history }\end{array}$} & \multirow{2}{*}{$\begin{array}{l}\text { Injury } \\
\text { type }\end{array}$} & \multirow{2}{*}{$\begin{array}{l}\text { Cause } \\
\text { of } \\
\text { injury }\end{array}$} & \multirow{2}{*}{$\begin{array}{l}\text { Operating } \\
\text { time } \\
\text { (min) }\end{array}$} & \multirow{2}{*}{$\begin{array}{l}\text { Blood } \\
\text { loss } \\
\text { (ml) }\end{array}$} & \multirow[t]{2}{*}{ Complication } & \multicolumn{2}{|c|}{ Walking ability } & \multirow{2}{*}{$\begin{array}{l}\text { T- } \\
\text { score }\end{array}$} & \multirow{2}{*}{$\begin{array}{l}\text { Osteoporosis } \\
\text { treatment }\end{array}$} \\
\hline & & & & & & & $\begin{array}{l}\text { Pre- } \\
\text { injury }\end{array}$ & $\begin{array}{l}\text { Final } \\
\text { follow-up }\end{array}$ & & \\
\hline $81 / F$ & None & $\Downarrow c$ & Fall & 51 & 1 & $\begin{array}{l}\text { Wound } \\
\text { dehiscence }\end{array}$ & $\begin{array}{l}\text { Without } \\
\text { aid }\end{array}$ & Cane & -3.1 & Romosozumab \\
\hline 79/M & $\begin{array}{l}\text { Colon } \\
\text { cancer }\end{array}$ & $\nabla c$ & Fall & 60 & 10 & $\begin{array}{l}\text { Wound } \\
\text { dehiscence }\end{array}$ & $\begin{array}{l}\text { Without } \\
\text { aid }\end{array}$ & $\begin{array}{l}\text { Without } \\
\text { aid }\end{array}$ & - & - \\
\hline $84 / F$ & $\begin{array}{l}\text { Heart } \\
\text { failure }\end{array}$ & 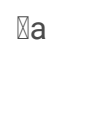 & Fall & 58 & 1 & $\begin{array}{l}\text { Lower } \\
\text { gastrointestinal } \\
\text { bleeding }\end{array}$ & $\begin{array}{l}\text { Without } \\
\text { aid }\end{array}$ & Wheelchair & -3.2 & Teriparatide \\
\hline $85 / F$ & $\begin{array}{l}\text { Diabetes } \\
\text { mellitus }\end{array}$ & $\nabla b$ & Fall & 59 & 1 & - & $\begin{array}{l}\text { Without } \\
\text { aid }\end{array}$ & $\begin{array}{l}\text { Without } \\
\text { aid }\end{array}$ & -3.2 & Teriparatide \\
\hline $84 / F$ & $\begin{array}{l}\text { Diabetes } \\
\text { mellitus }\end{array}$ & $\nabla b$ & Unclear & 90 & 1 & - & $\begin{array}{l}\text { Without } \\
\text { aid }\end{array}$ & $\begin{array}{l}\text { Without } \\
\text { aid }\end{array}$ & -3.0 & Teriparatide \\
\hline $84 / F$ & $\begin{array}{l}\text { Parkinson } \\
\text { disease }\end{array}$ & $\nabla b$ & Fall & 68 & 1 & - & Circle & Circle & -3.9 & Denosumab \\
\hline $73 / F$ & $\begin{array}{l}\text { Thyroid } \\
\text { cancer }\end{array}$ & $\otimes b$ & Fall & 41 & 1 & - & $\begin{array}{l}\text { Without } \\
\text { aid }\end{array}$ & Cane & -3.6 & - \\
\hline $76 / F$ & $\begin{array}{l}\text { Hepatic } \\
\text { cancer }\end{array}$ & $\nabla \mathrm{b}$ & Unclear & 52 & 1 & - & $\begin{array}{l}\text { Without } \\
\text { aid }\end{array}$ & Cane & - & Denosumab \\
\hline $78 / F$ & $\begin{array}{l}\text { Breast } \\
\text { cancer }\end{array}$ & $\nabla \mathrm{b}$ & Unclear & 68 & 1 & $\begin{array}{l}\text { Deep vein } \\
\text { thrombosis }\end{array}$ & $\begin{array}{l}\text { Without } \\
\text { aid }\end{array}$ & $\begin{array}{l}\text { Without } \\
\text { aid }\end{array}$ & -4.1 & Romosozumab \\
\hline
\end{tabular}

\section{Representative cases}

An 85-year-old female with hypertension and diabetes mellitus fell from a standing height and was diagnosed with non-specific low back pain and treated conservatively with analgesics. Two months after the trauma, she could not walk because of severe buttock and leg pain. CT showed left rami fracture, bilateral sacral ala fractures and S3 vertebral fracture (Rommens classification type IVb FFP) (Fig. 2). We treated her using this MIS technique on the 9th day after admission. The surgical time was 58 minutes, and the intraoperative blood loss was $1.0 \mathrm{ml}$. She was allowed to walk with full weight bearing 2 weeks after the surgery; at 6 months postoperatively, complete bone union was achieved, and she was ambulatory without symptoms (Fig. 3).

\section{Discussion}

The number of FFP is increasing quickly due to the ageing of society. Previously, conservative treatment had been considered a standard treatment for FFP, providing good clinical results. However, the outcomes in elderly and severe osteoporotic patients who experience nonunion and fracture progression of the pelvic ring of prolonged pain and pain-induced immobility during conservative treatment are not rare, and long-term immobilization can lead to secondary systemic complications such as aspiration pneumonia and urinary tract infection. Rommens developed a comprehensive classification for FFP with suggestions for the management of each injury type ${ }^{6}$. Type I FFP can be treated conservatively. For type II FFP, conservative treatment is recommended initially, and percutaneous fixation is required when conservative treatment is not successful. Type III and IV injuries require surgical treatment. However, conventional ORIF is highly invasive and not necessarily safe for elderly patients with poor general conditions. It has been a desire to make the surgery less invasive. Toda et al. reported a mean surgical time of 129 minutes with an intraoperative blood loss of $223 \mathrm{ml}$ for posterior pelvic-ring stabilization in unstable pelvic ring fractures using the transiliac rod and screw fixation technique ${ }^{7}$. Similar results were reported by Okuda et al. (158 minutes and $299 \mathrm{ml}$ using the crab-shaped fixation technique) ${ }^{8}$. These surgical techniques are less invasive than conventional ORIF but are still highly invasive for frail patients. In this study, the use of our novel MIS technique further decreased the surgical time and intraoperative blood loss (mean surgical time and intraoperative blood loss were 60.7 minutes and $2.0 \mathrm{ml}$, respectively), which has an advantage for FFP in elderly patients with poor conditions. Full weight bearing is allowed 2-4 weeks postoperatively, which means that sacral bone healing progresses because the stiffness of our stabilization is less than that of transiliac screw and rod fixation and crab-shaped fixation. Although immediate postoperative full weight bearing is difficult, surgical stabilization of the unstable pelvic ring provides adequate pain 
relief and early mobilization, such as posture changes, maintaining a sitting position and wheelchair transfer. Our MIS technique is beneficial, especially in elderly and frail patients, to avoid long-term immobilization and subsequent systemic complications.

\section{Conclusion}

We reported a new MIS technique for the treatment of FFP. This method is a successful and sufficient minimally invasive option for highrisk elderly patients.

\section{Methods}

\section{Ethical consideration.}

The study protocol was approved by the institutional review board of Hokkaido Spinal Cord Injury Center and performed in accordance with Declaration of Helsinki. Informed consent was obtained from all participants. And specific consent for both study participation and publication of identifying information in an online open-access publication was obtained from the female of representative case.

\section{Patients.}

This study consisted of 9 patients with FFP who were treated with surgical posterior pelvic ring stabilization with our novel MIS technique between October 2015 and April 2019. There were 8 females and 1 male, and the average age was 80.8 years (range $73-83$ years). The average follow-up period was 10.0 months (range 3-32 months). All fractures were classified according to the Rommens fracture classification. The distribution of fracture types at the time of admission was 1 type IIlc fracture, 1 type IVa, 6 type IVb and 1 type IVc. The following variables were used to evaluate the clinical outcomes of this new stabilization technique: surgical time, intraoperative blood loss, postoperative complications, bony union rate, change in walking ability before and after injury, bone mineral density (BMD) of the lumbar spine or total hip (T-score) and treatment of osteoporosis.

\section{Declarations}

\section{Conflict of interest:}

The authors declare that they have no conflict of interest.

\section{Funding:}

There is no funding source.

\section{References}

1. Kannus, , Parkkari, J., Niemi, S. \& Sievanen, H. Low-trauma pelvic fractures in elderly Finns in 1970-2013. Calcif Tissue Int. 97(6), 577580 (2015).

2. Nanninga, GL., de Leur, K., Panneman, MJM., van der Elst, M. \& Hartholt, KA. Increasing rates of pelvic fractures among older adults: the Netherlands, 1986-2011. Age Ageing. 43(5), 648-653 (2014).

3. Sullivan, MP., Baldwin, KD., Donegan, DJ., Mehta, S. \& Ahn, J. Geriatric fractures about the hip: divergent patterns in the proximal femur, acetabulum, and pelvis. Orthopedics. 37(3),151-157 (2014)

4. Maier, GS. et al. Risk factors for pelvic insufficiency fractures and outcome after conservative therapy. Arch Gerontol Geriatr. 67, 80-85 (2016).

5. Rommens, PM. et al. Progress of instability in fragility fractures of the pelvis: An observational study. Injury. 50(11), 1966-1973 (2019).

6. Rommens, PM \& Hofmann, A. Comprehensive Classification of Fragility Fractures of the Pelvic Ring: Recommendations for Surgical Treatment. Injury. 44(12),1733-1744 (2013).

7. Toda, K., Yagata, Y., Kikuchi, T., Takigawa, T. \& Ito, Y. Minimally Invasive Surgery for Unstable Pelvic Ring Fractures: Transiliac Rod and Screw Fixation. Acta Med Okayama. 74(1), 27-32 (2020) 
8. Okuda, A. et al. Minimally Invasive Spinopelvic "Crab-Shaped Fixation" for Unstable Pelvic Ring Fractures: Technical Note and 16 Case Series. J Orthop Surg Res, 14(1), 51 (2019).

\section{Figures}
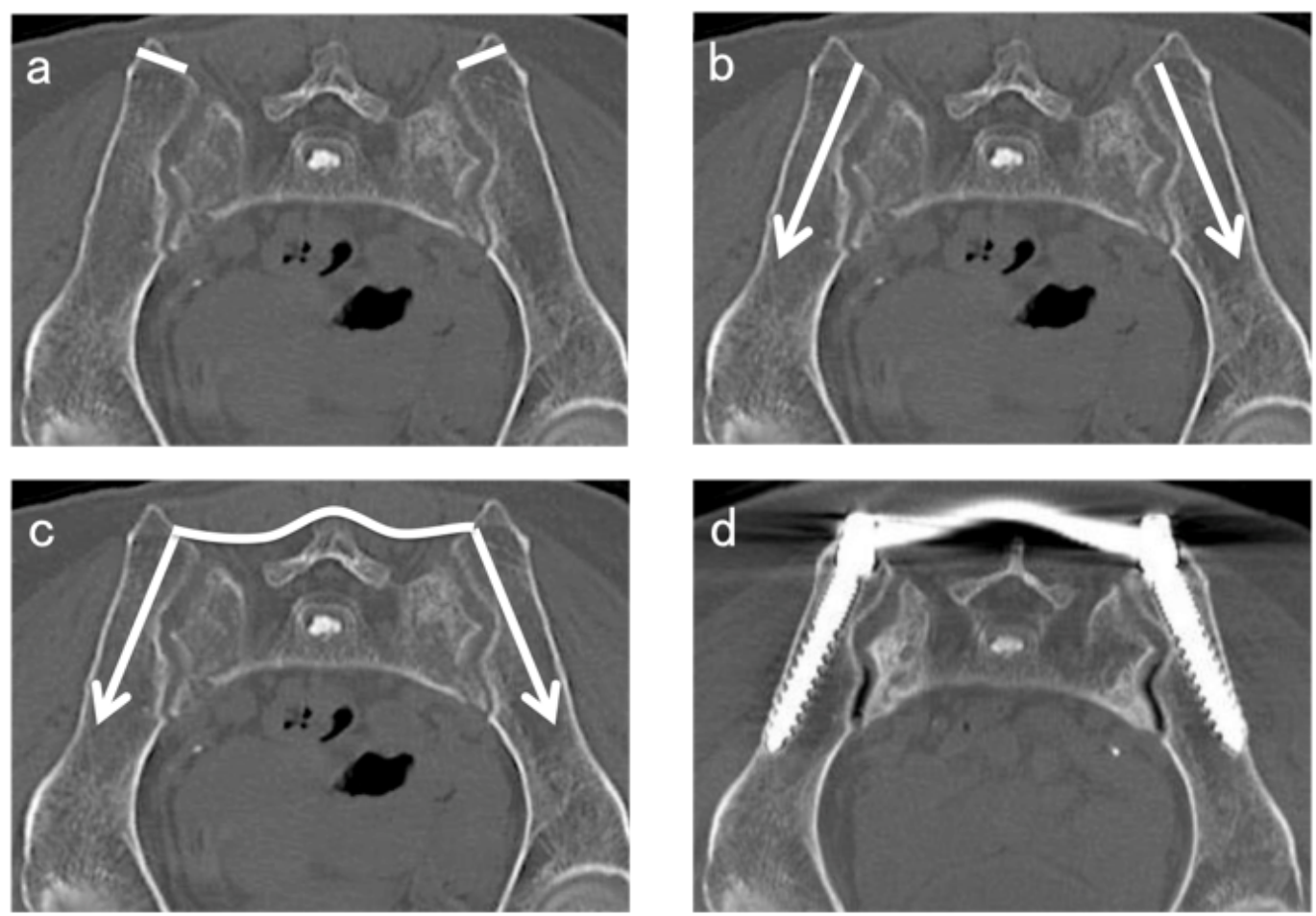

\section{Figure 1}

a. Minimal bone resection of top of the posterior superior iliac spine. b. White arrows indicate insertion of the iliac screws. c. Placement and fixation of W-shaped bent rod connecting the iliac screws. d. Postoperative CT image.
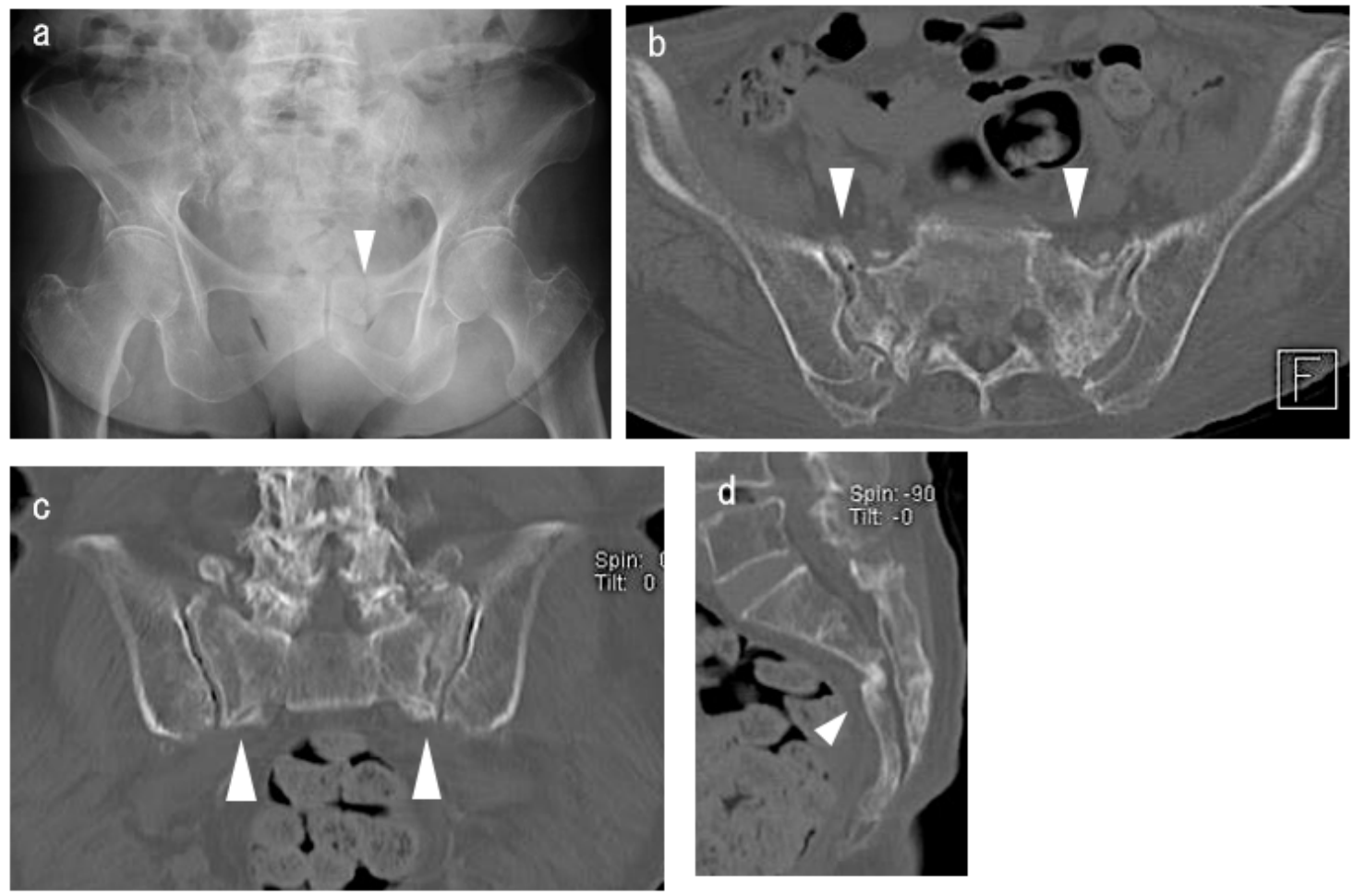


\section{Figure 2}

85 year-old-female who sustained a type 『b FFP. a. Anteroposterior radiograph showing left rami fracture. b,c,d. Cross-sectional axial, coronal and sagittal plane of the spiral CT showing bilateral sacral ala fractures and S3 vertebral fracture.
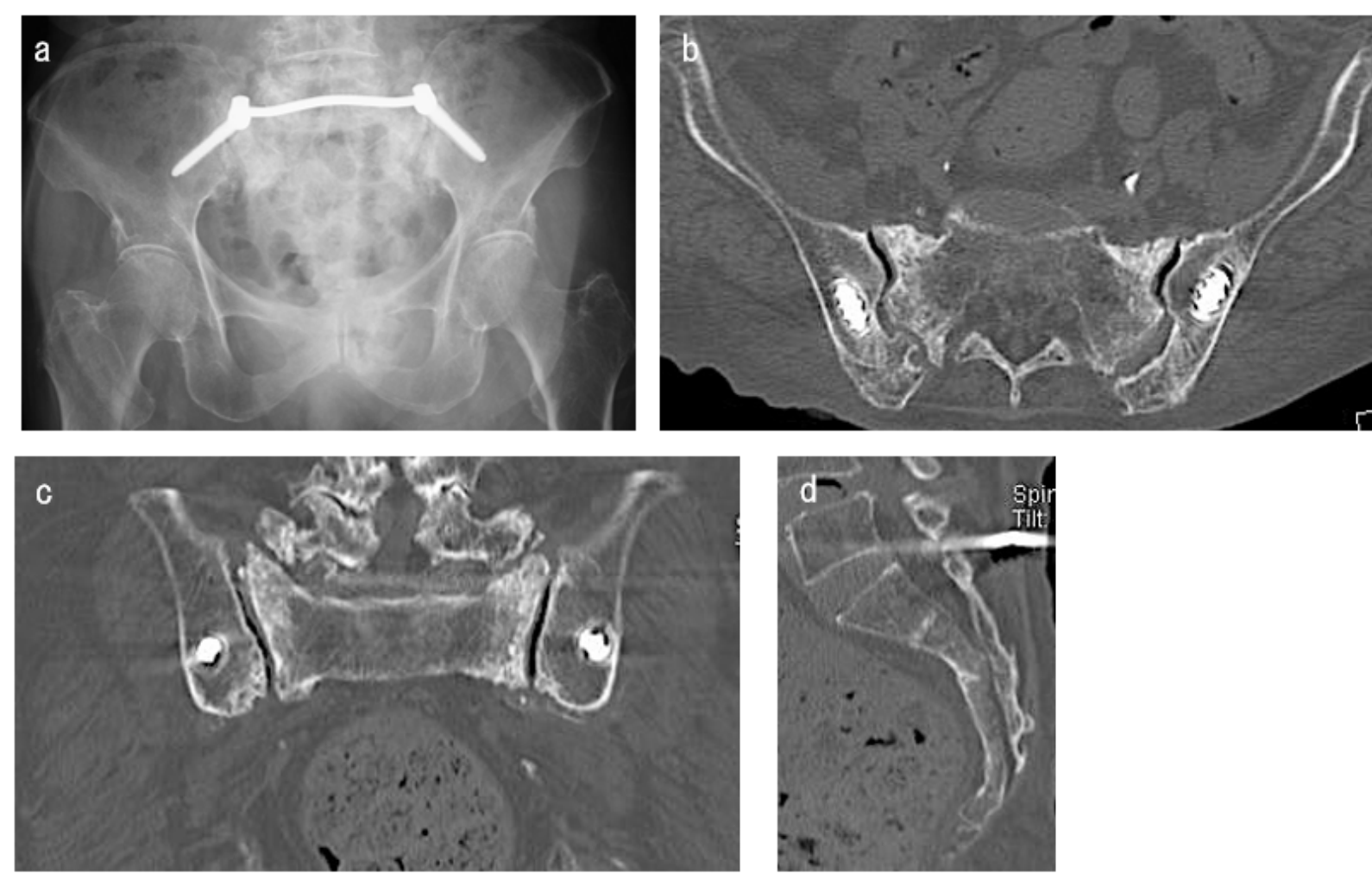

\section{Figure 3}

a. Anteroposterior radiograph just after the surgery. b,c,d. Axial, coronal and sagittal plane of the spiral CT 6 months after the surgery. 